\title{
Assessment of the Potential Occurrence of Dry Period in the Long Term for Pahang State, Malaysia
}

\author{
Ahmad Saifuddin Othman ${ }^{1,2, *}$, and Nurul Nadrah Aqilah Tukimat ${ }^{1}$ \\ ${ }^{1}$ Universiti Malaysia Pahang, Faculty of Civil Engineering and Earth Resources, 26300 Gambang, Kuantan Malaysia \\ ${ }^{2}$ Universiti Malaysia Pahang, Centre for Earth Resources Research and Management, 26300 Gambang, Kuantan Malaysia
}

\begin{abstract}
The interference of climate circulation and continuous rising of surface temperature every year has caused the atmosphere composition change which gives serious impact to water resource management. Pahang is among of the affected states by El Nino that hit Malaysia in recent years which led to water depletion at several water plants. Based on the current situation, this study focuses on 1) simulate the average rain pattern using statistical downscaling; 2) identify the severity index and dry duration occurrence in the catchment area. Predicting potential changes in the climate events is important to evaluate the level of climate change in the critical region. Therefore, the integration of Statistical Downscaling Model (SDSM) and Standard Precipitation Index (SPI) have been conducted to study the potential occurrence of the dry period due to climate change for year 2020s and year 2050s. The results reveal that the dry condition is high during the mid-year. The lowest SPI value is estimated to reach -2.2 which can be classified as extreme. The potential dry period is expected to increase $2.5 \%$ and $3.3 \%$ in 2020 and 2050 , respectively.
\end{abstract}

\section{Introduction}

Nowadays, climate change has become the important issue due to its impact on the ecosystem, water resources, environment and human life [1]. The probability of climate change of an area also refers to the historical condition or the projection of future climates such as monsoons, droughts and floods. Climate change refers to the continuous change in natural climate variability properties in long term due to changes in the global climate as a result of human activities [2]. Industrial advancement is one of the main factors that led to the uncontrolled greenhouse gas emissions especially carbon dioxide (CO2) thereby raising the world temperature. The enhancement of $\mathrm{CO} 2$ was measured by computing the hydrogen ion of sea water concentration which showed a reduction in $\mathrm{pH}$ value to 0.1 which equivalent to an increase of $26 \%$ of acid [3]. The dramatic increase in temperature due to climate change will cause high evapotranspiration which affects the water resources $[4$, $5,6]$. In the 20th century, the temperature is expected to increase more than $2^{\circ} \mathrm{C}$ in the tropical and temperate regions and more than $4^{\circ} \mathrm{C}$ globally. This will threaten the global security [3]. The projected mean surface temperature in Malaysia is expected to be higher with an average increase of $0.6^{\circ} \mathrm{C}-1.2^{\circ} \mathrm{C}$ [7]. Drought is a natural phenomenon that occurs directly but the impact to the region and the occurrence frequency are the features that distinguished from other phenomena. Dry basis is the long term dry conditions with low moisture content which the studies indicate that the information of rainfall and temperature changes.

General Circulation Models (GCMs) is a method developed in the present, for the purpose of projections of climate change scenarios studied by the scale set. The uses of GCMs need to be identified in order to focus and narrow down the grids to get the right hydrological cycle information at site studied. Statistical downscaling model, the National Centers for Environmental Prediction (NCEP) data have been used in designing the predictorpredictant relationship and GCM data provided by Canadian Centre for Climate Modeling and Analysis (CCCma) used to project the climatic changes due to greenhouse gases (GHGs) contribution in the future year $[8,9]$. Two main approaches for a downscaling model are dynamical downscaling (DD) and statistical downscaling (SD). In this study, statistical downscaling techniques have been chosen and the universally multiple linear regression models called Statistical Down-Scaling Model (SDSM).

There are many future climate change projection studies conducted globally such as Sylhet and Moulvibazar districts in North-eastern region of Bangladesh [10], Marsyangdi River Basin, Nepal [11] and Lisbon [12]. While in Malaysia, the studies in the Muda Irrigation Scheme in north of peninsular Malaysia by $\mathrm{N}$. N. A. Tukimat et al. [13] and the Kurau River by Hasan et al. [14] are the preliminaries studies available in Malaysia at this time. The study is initiated by Hassan et al. [14] in Kurau River are conducted to assess the impact

*Corresponding author: othman.ibnu@yahoo.com 
of future climate change that may affect a dam which located at the downstream of the river. The dam is main water supply to meet domestic and industrial demands at Kerian District as well as Larut Matang District. The impact are concerned may also disturb the irrigation water for double cropping planting intensity to the Kerian-Sg. Manik irrigation scheme as rice cultivation is the main economic activity in that area. The study also conducted at several cropping areas in Malaysia including Alor Setar (Kedah), Subang (Selangor) and Senai (Johor) in order to investigate the irrigation water demand changes in an intensive irrigated area of Malaysia under climate change scenario [15]. Pahang experienced the latest dry event in 2016 which affects four plants around Pahang which are Lubuk Kawah Water Plant in Temerloh, Jelai and Batu 9 Water Plant in Lipis and Chini Water Plant in Pekan, Pahang. This study focuses on 1) simulate the average rain pattern using statistical downscaling; 2) identify the severity index and dry duration occurrence in the catchment area. Hence, the projection study on severity index and dry occurrence pattern are conducted in Pahang state to provide significant information for water resources management in facing the uncertain climate changes.

\section{Background Theories}

This steps using statistical downscaling model (SDSM) described by Z.Hassan et al. [14] which defined the rainfall occurs on each day or not as shown below:

$$
W_{t}=\propto_{0}+\sum_{j=1}^{n} \propto_{t-1} \hat{u}_{t}^{(j)}+\propto_{t-1} w_{t-1}
$$

Where $t$ is time [days], $W_{t}$ is the conditional possibility of rain occurrence on day $t, \hat{\mathrm{u}}_{t}^{(j)}$ is the normalized predictor, $\alpha_{j}$ is the regression parameter deduced by an ordinary least square method, and $W_{t-1}$ and $\alpha_{t-1}$ are the conditional probabilities of rain occurrence on day $t-1$ and lag- 1 day regression parameter, respectively based on the studied region and predictand. The uniformly distributed random number $r_{t}\left(0 \leq r_{t} \leq 1\right)$ was used to determine the rain occurrence and the possibility that the rain would happen if $w_{t} \leq r t$. The estimated value of rainfall on each rainy day is determined. This can be represented with a $\mathrm{z}$ score:

$$
Z_{t}=\beta_{0}+\sum_{j=1}^{n} \beta_{j} \hat{u}_{t}^{(j)}+\beta_{t-1}+\varepsilon
$$

where, $Z_{t}$ is the $\mathrm{z}$-score on day $\mathrm{t}, \beta_{\mathrm{j}}$ is the calculated regression parameter, and $\beta_{\mathrm{t}-1}$ and are $\mathrm{Z}_{\mathrm{t}-1}$ are the regression parameter and the $\mathrm{Z}$-score on day $t-1$, respectively. Thus, rainfall $y_{t}$ on day t can be written as:

$$
y_{t}=F^{-1}\left[\varnothing\left(Z_{t}\right)\right]
$$

where, $\varnothing$ is the normal cumulative distribution function and $\mathrm{F}$ is the empirical function of $y_{t}$. A transformation of the fourth root was applied, to take account of the skewed nature of the rainfall distribution. During the model development (calibration) of SDSM, some parameters such as event threshold and variance inflation were adjusted in order to obtain the good agreement between observed and simulated climate variables.

\section{Study Area}

Pahang is one of the state which located at $4^{\circ} 11^{\prime} 10^{\prime} \mathrm{N}$ and $104^{\circ} 03^{\prime} 45^{\prime}$ ' $\mathrm{E}$ on the east coast of Peninsular Malaysia. Pahang State with area $35,965 \mathrm{~km}^{2}$ as shown in Figure 1. The area experienced wet and dry seasons throughout the year due to its geographical position which located in equator lines. The climatic cycle in the region is influenced by four seasonal changes, known as the monsoon season. The northeast monsoon and the southwest monsoon are two major monsoon that occurs every year with two inter monsoons [16].

The prediction of highest and lowest seasonal average temperature for Peninsular Malaysia until this 20th century is $3.7^{\circ} \mathrm{C}$ and $3.3^{\circ} \mathrm{C}$, respectively [17]. The average global surface temperature is projected will increase by $1.4^{\circ} \mathrm{C}$ to $5.8^{\circ} \mathrm{C}$ over the period 1990 to 2100 [2]. Total rainfall for three consecutive months from July to September recorded at $151.30 \mathrm{~mm}, 141.10 \mathrm{~mm}$ and $142.39 \mathrm{~mm}$, respectively.

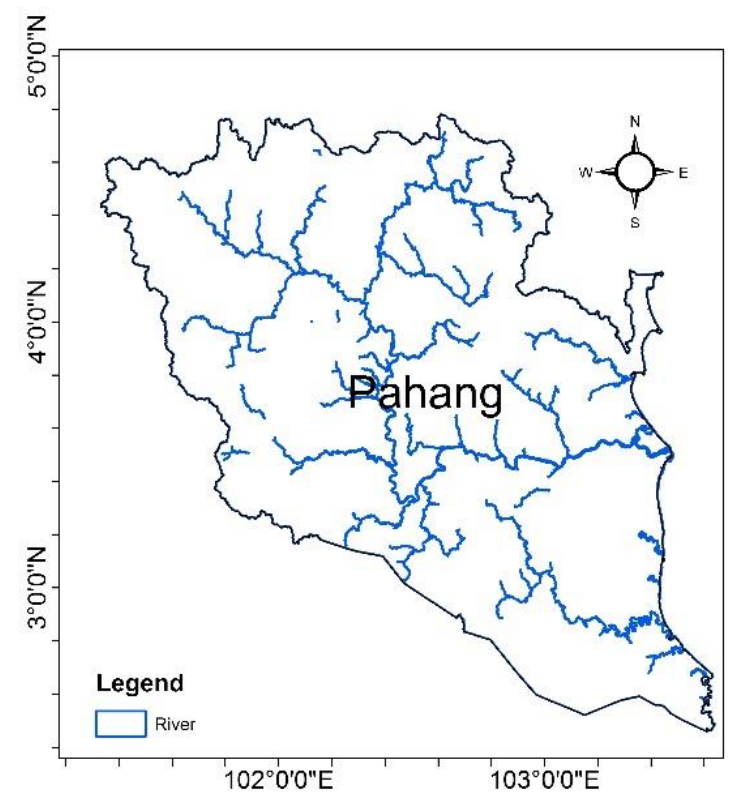

Fig. 1. Locations of Pahang state

\section{Methodology}

\subsection{Data and Sources}

12 rainfall stations are selected in this study after the screening process that only considered below $1 \%$ missing data. The rainfall stations were selected due to the completion of history data for 30 years. Table 1 shows the list of rainfall stations used in this study which cover the whole of Pahang State. All stations are monitored by the Department of Irrigation and Drainage (DID) of Malaysia. The prediction of rainfall for year 2010 to 2069 (60 years) are using the historical data from the year 1979 to 2008 
(30 years). The historical data then divided by two sets of a time period which are (1979-1993) and (1994-2008). The first 15 years (1979-1993) was used in the calibration process, while the other 15 years (1994-2008) for validation purpose. The historical data and NCEP parameters are used to obtain the relationship between local climate pattern and information of the atmospheric circulation by mathematical model simulation. The SDSM model generates the synthetic precipitation for 12 rainfall stations. Multiple regression techniques were used in the SDSM model to construct the predictor-predictand relationship. The hydrological data such as rainfall, inflow, spill, seepage, water level and water release were purchased from Department of Irrigation and Drainage (DID) of Malaysia.

Table 1. Details rainfall stations at Pahang State

\begin{tabular}{cccc}
\hline & & \multicolumn{2}{c}{ Coordinate } \\
NO & Station ID & Latitude & $\begin{array}{c}\text { Longitude } \\
(\mathrm{N})\end{array}$ \\
\cline { 3 - 4 } & & $3^{\circ} 54^{\prime}$, & $103^{\circ} 08^{\prime}$, \\
\hline 1 & 3931014 & $4^{\circ} 07^{\prime}$ & $102^{\circ} 12^{\prime}$, \\
2 & 4122067 & $4^{\circ} 21^{\prime}$ & $102^{\circ} 04^{\prime}$, \\
3 & 4320066 & $3^{\circ} 23^{\prime}$ & $102^{\circ} 32^{\prime}$, \\
4 & 3325086 & $3^{\circ} 29^{\prime}$ & $103^{\circ} 08^{\prime}$, \\
5 & 3431099 & $3^{\circ} 29^{\prime}$ & $102^{\circ} 56^{\prime}$, \\
6 & 3429096 & $3^{\circ} 32^{\prime}$ & $103^{\circ} 14^{\prime}$, \\
7 & 3532101 & $3^{\circ} 10^{\prime}$ & $102^{\circ} 14^{\prime}$, \\
8 & 3122142 & $3^{\circ} 19^{\prime}$ & $101^{\circ} 51^{\prime}$, \\
9 & 3318127 & $3^{\circ} 12^{\prime}$, & $102^{\circ} 09^{\prime}$, \\
10 & 3221001 & $4^{\circ} 31^{\prime}$, & $101^{\circ} 25^{\prime}$ \\
11 & 4514032 & $4^{\circ} 26^{\prime}$ & $101^{\circ} 27$ \\
12 & 4414038 & & \\
\hline
\end{tabular}

\subsection{Statistical downscaling tool}

A spatial data of GCMs were used in SDSM to downscale the daily scenarios from the predictor-predictand relationships. The predictor variables such as Climate Model Inter-comparison Project Phase 5 (CMIP 5) provide daily information concerning the large-scale state of the atmosphere, while the predictand such as rainfall describes the condition at the regional scale. Daily local rainfall data are required at least 30 years historical data to generate the future climate trend based on the emission level in the region. This model implies the statistical relationships to downscale the large-scale resolutions of GCMs denoted as predictors into the local climate variables known as predictand. It allowed the raw data to transform into standard predictor variables to produce nonlinear regression models before calibration and validation steps were applied. The data series can also be shifted forward or backward by any number of time steps to produce lagged predictor variables.

The major challenge in climate downscaling especially in extreme rainfall indices is a selection of appropriate predictors. The predictors are expected to be highly correlated with extreme rainfall indices. Furthermore, the predictors should be accurately projected by available GCMs for the future projection of climate. There are no general guidelines for the selection of predictors in different parts of the world and therefore, a comprehensive search of predictors is necessary. Rainfall is set to be as conditioning process because there is an intermediate process between the regional forcing and local weather, which the local rainfall amount is correlated with the occurrence of wet days. As the distribution of rainfall is skewed, a fourth root transformation is applied to the original series to convert it to the normal distribution, before applying the regression analysis. Table 2 shows the predictors variables in the downscaling experiments.

Table 2. List of predictors variables

\begin{tabular}{ccc}
\hline No & Predictors & Code \\
\hline 1 & Surface Meridional Velocity & $\mathrm{p}_{-} \mathrm{v}$ \\
2 & Surface Vorticity & $\mathrm{p}_{-} \mathrm{z}$ \\
3 & Surface Wind Direction & $\mathrm{p}$ th \\
4 & $500 \mathrm{hPa}$ Zonal Velocity & $\mathrm{p} 5 \_\mathrm{u}$ \\
5 & $500 \mathrm{hPa}$ Meridional Velocity & $\mathrm{p} 5 \_\mathrm{v}$ \\
6 & $500 \mathrm{hPa}$ Vorticity & $\mathrm{p} 5 \_\mathrm{z}$ \\
7 & $500 \mathrm{hPa}$ Wind Direction & $\mathrm{p} 5$ thgl \\
8 & $850 \mathrm{hPa}$ Meridional Velocity & $\mathrm{p} 8 \_\mathrm{v}$ \\
9 & $850 \mathrm{hPa}$ Vorticity & $\mathrm{p} 5 \_\mathrm{z}$ \\
10 & $850 \mathrm{hPa}$ Geopotential Height & $\mathrm{p} 850$ \\
11 & $850 \mathrm{hPa}$ Wind Direction & $\mathrm{p} 8 \mathrm{th}$ \\
12 & Specific Humidity at $850 \mathrm{hPa}$ & $\mathrm{s} 850$ \\
& Height & \\
13 & Surface Specific Humidity & shum \\
\hline
\end{tabular}

\subsection{SPI Method}

Standardized Precipitation Index was created by T.B. McKee, N.J. Doesken, and J. Kleist [18]. This method is very flexible to be able to monitor the state of a variety of time scales. SPI has been used to study the effects of rainfall which is fall to be as underground water, reservoir storage, soil moisture, and water discharge. The index which looks forward to the probability of rainfall for varies time scale. Thus, SPI considers the time scale in the calculation the drought index such as $1,3,6,9,12,24$, and 48 time scales that represents the number of the month. The spi-1 is the percentage of normal rainfall for the period of 30 days. The value of 1 -month obtained is more accurate because monthly distribution is a regular cycle. This calculation is short-term closely related to soil moisture. SPI-1 month calculation is suitable with the catchment area condition has to decrease monthly rainfall value. This SPI variation value to negative or positive more uniform because reducing monthly rainfall difference percentage. 


\section{Results and Discussions}

\subsection{Calibration and Validation Analysis}

Figure 2 and 3 show the simulated results produced for calibration (1979-1993) and validation (1994-2008) processes using NCEP predictor variables compared to observed data. There are 5 parameters used in calibration process include 1) specific humidity at $850 \mathrm{hPa}$ height; 2) surface specific humidity; 3) 500hPa zonal velocity; 4) surface vorticity and 5) surface meridional velocity. The graphs result of calibration and validation indicate that the observed rainfalls are very close to the simulated results. For calibration, the annual calibrated shows the slight decrease of rainfall than the observed rainfall recorded with $28.58 \mathrm{~mm}$. While, the validation part shows the increment of rainfall with $17.8 \mathrm{~mm}$. The difference between the simulated and observed data are affected by the climate change. The percentage of calibrated and validated error are $1.34 \%$ and $0.81 \%$, respectively. The amount of rainfall in the calibration period used was higher than the amount of rainfall in the validation period. However, this model is applicable to use as the validation error are reduced to $0.81 \%$ from $1.34 \%$ in the calibration process. These results show that the projection analysis results are acceptable at this stage.

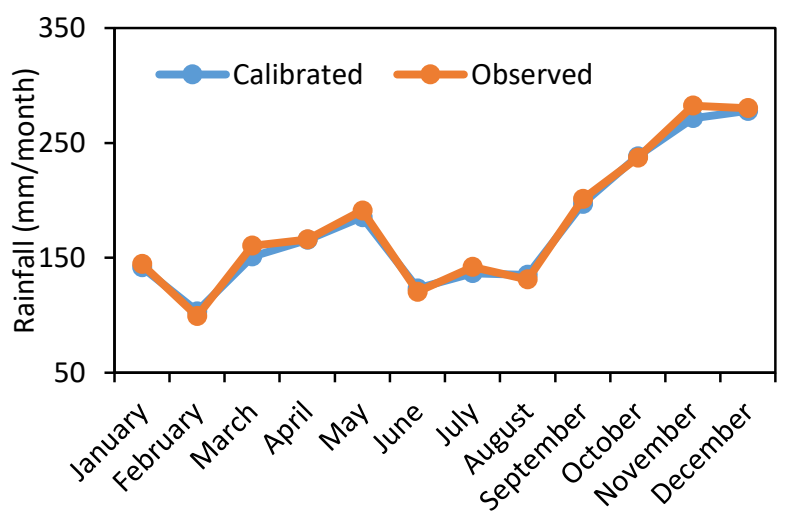

Fig. 2. Results of calibrated rainfall (1979 to 1993)

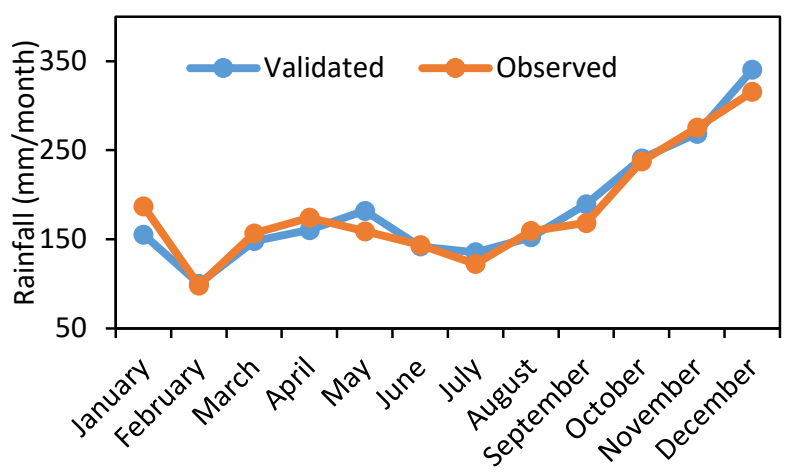

Fig. 3. Results of validated rainfall (1994 to 2008)

\subsection{Performances of Projected Rainfall by AR5 Scenarios}

Figure 4 present the constant predictors used to project the future rainfall trend in the same grid box provided by AR5 type 26, 45 and 85 scenarios. The scenarios are divided based on radiative forcing quantities concentrations in a region of up to the year 2100 . The diversity of scenarios in the simulation resulting in diverse analysis results in each study area. This graph compares the annual historical rainfall data in the year 2010 with the annual prediction of total rainfall in the year 2010 at Pahang State. After data screening process, 2010 was identified as the year with the complete rainfall history data for all rain stations. The graph shows that the projection and historical pattern are quite similar. It shows that the decreasing amount of rainfall until the end except in month February, October and November. The simulated rainfall for month February, October and November were estimated to increase more than the historical rainfall recorded in February, October and November with $47.3 \mathrm{~mm}, 96.8 \mathrm{~mm}$ and $33.8 \mathrm{~mm}$, respectively. The percentage error difference of this 3 months are $48.3 \%, 39.0 \%$ and $11.6 \%$. The historical total rainfall in other month shows the difference result with the slightly percentage error compared to projected rainfall with January (2.4\%), March (11.8\%), April (23.6\%), May (5.9\%), June (35.5\%), July (23.7\%), August (13.2\%), September $(20.1 \%)$, and December $(5.6 \%)$. However, the annual projection rainfall percentage decrease with $185.28 \mathrm{~mm}$ and $7.98 \%$ error differences. SDSM Model are specialized in analysing the future pattern based on the normal cycle of hydrology historical pattern. Thus, the disaster event will not be analysed. Moreover, disaster event such as flood, flash flood, landslide, thunderstorm and so on are rare and unexpected conditions. The projection analysis the model is reliable to project the future rainfall.

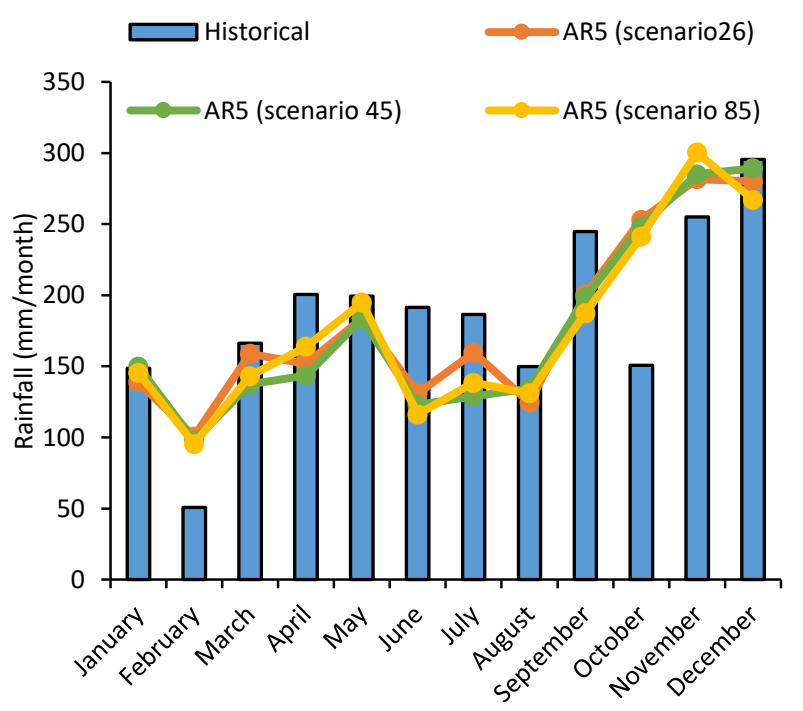

Fig. 4. Performance of annual monthly total rainfall (mm) against historical data in year 2010 


\subsection{Climate Simulation and Projection}

The prediction of rainfall in the Pahang State for 60 years are covered from year 2010 to 2069 which divided into two periods of time with 15 years each. The mid year of two periods which are 2020s (2010-2039) and 2050s (2040-2069) are used for future pattern analysis. The result of future emission downscaling are shown in Figure 5 and Figure 6 . The 100 ensembles of synthetic daily time series are produced for AR5 (26, 45 and 85 scenarios). The figures also show the average history rainfall data for 30 years (1979-2008) by monthly basis. The figures reveal that the rainfall increasing thread in all future time horizons in overall months except February and June to August. The rainfall intensity achieved $47.8 \%$ in February and $13.4 \%$ to $56.5 \%$ in June to August in year 2020 s. Meanwhile, in the year 2050s rainfall intensity achieved $48.0 \%$ in February and $13.8 \%$ to $56.3 \%$ in June to August. The heaviest rainfall is expected to occur in December during Northeast season. However, the rainfall intensity is predicted to become lesser in year 2020s and 2050s achieve $8.1 \%$ and $8.6 \%$ respectively compare to the historical rainfall.

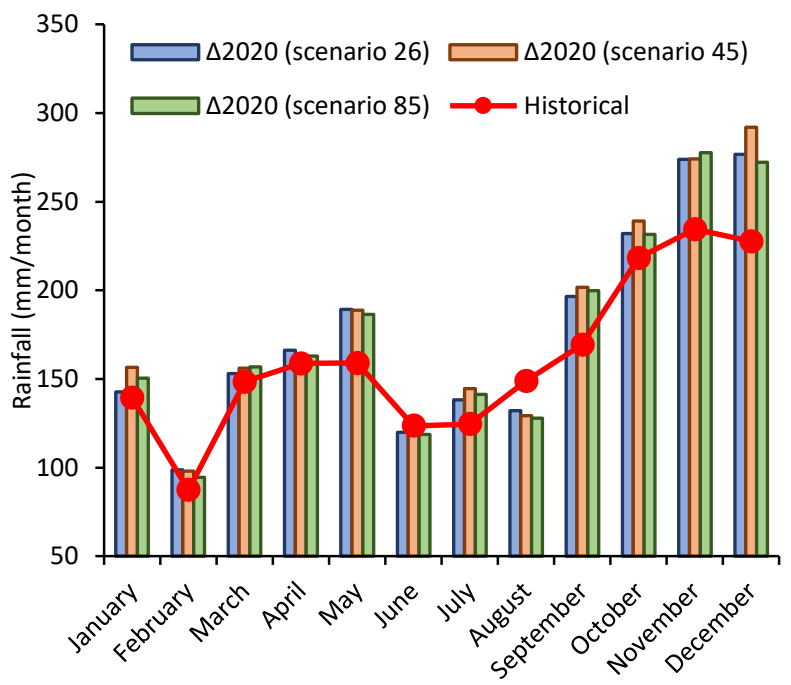

Fig. 5. Average annual rainfall at year $\Delta 2020$ s

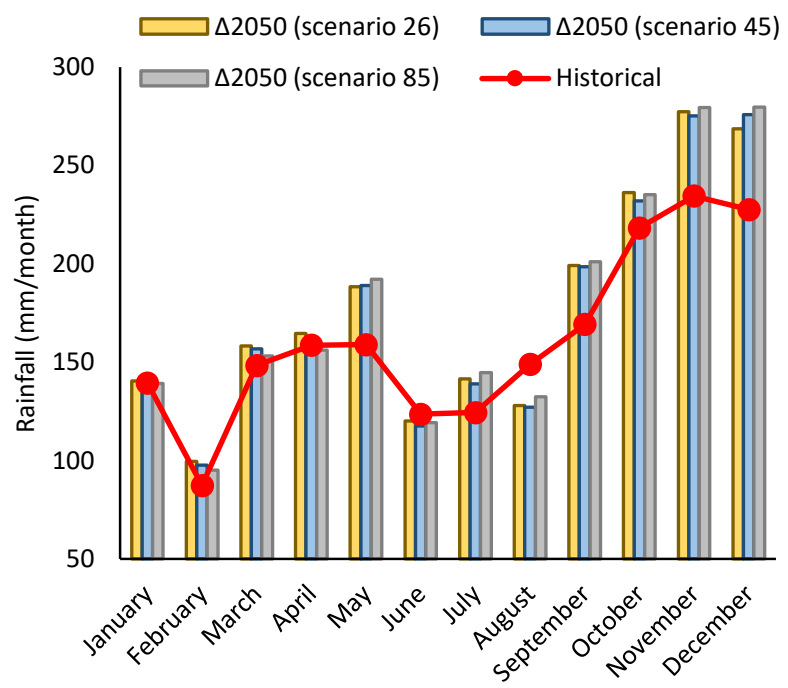

Fig. 6. Average annual rainfall at year $\Delta 2050$ s

\subsection{SPI Projection and Simulation}

The analysis used monthly rainfall simulation data for a minimum period of 30 years. Monthly rainfall simulation data for each selected station has been analysed before the SPI analysis can be carried out. Graph 7 and 8 are result of analysis SPI-1 value suitable with study carried out. SPI-1 values were plotted with the yearly time scale for the observed annual dry pattern. The analysis shows there is dry condition can be detected in the future year. Dry pattern that become increase in the middle of year. The SPI values in May and September are expected low and potentially to reach -2.2 and -1.5 , respectively. These conditions can be classified as extreme and severe dry pattern which might cause drought event. In the early year phase, the SPI value is expected to be normal between 1.1 to 1.2 . The percentage in the first period 2018 to 2039 year expect $2.5 \%$ dry pattern will potential. On the next period 2040 to 2069 years expectation condition increase of $3.3 \%$ dry pattern will potential in every 30 years. In generally, Southwest Monsoon from late May to September normally signifies relatively drier weather.

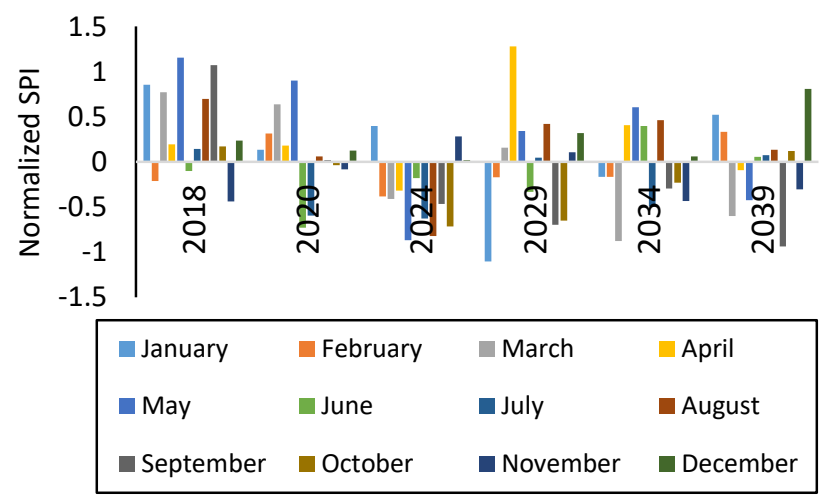

Fig. 7. SPI values for 1-month time scale at year 2018 to 2039

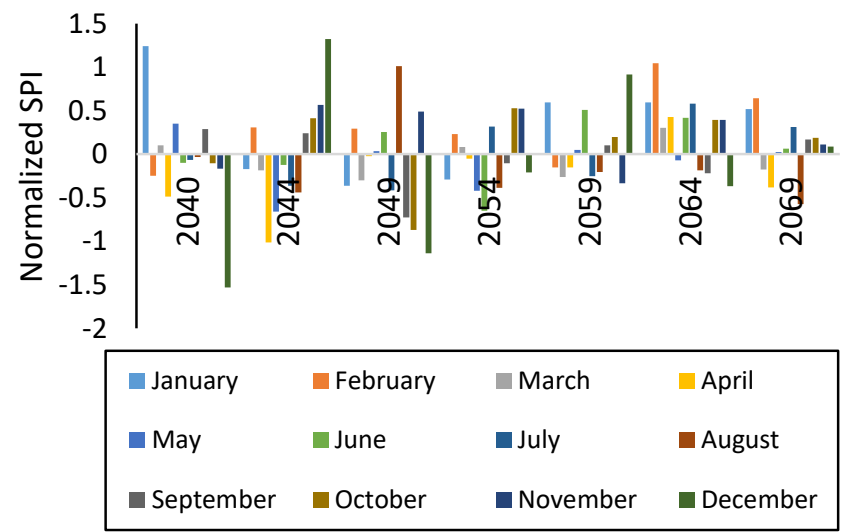

Fig. 8. SPI values for 1-month time scale at year 2040 to 2069

Rainfall data obtained are consistent data for analysis, although there are few missing data, but it can still provide a satisfactory and consistent results. Through this analysis, dry conditions have been detected in the catchment areas based on monthly depleted rainfall data. This analysis show the relation between dry conditions in the catchment to the rainfall distribution cycle. The SPI index is a simple method to apply because it only required 
rainfall data. Rainfall data will be analysed by using gamma distribution parameters to obtain the distribution of flows well. This calculation obtained the probability of cumulative flows for each station studied. However, the analysis of the drought level should be detailed by requiring other calculations such as the severity level to make the results more accurate and effective.

\section{Conclusions}

This study contributes towards the ability of the SDSM to project the future rainfall pattern and the dry future pattern estimation by using SPI. The correlation relationship method is proposed to manage the complexity of predictor selections in SDSM model. The General Circulation Model (GCMs) parameters were employed to project the climate trend which considered the estimated emission level projection in the future year. In general, the dry climates result in significant changes to monthly rainfall decrement which affect the future dry scenario in the catchment area. Through SPI analysis, a dry scenario was detected in a state on monthly rainfall data basis within 30 years. The dry pattern analysis in all station by using a consistent data provided has demonstrated the suitability in detecting a dry pattern occurred in this study area. Therefore, the effective water management planning is needed by the local authorities to face the climate changes challenges in the future.

The authors would like to thanks, Universiti Malaysia Pahang (UMP) for the funding support through grant number RDU150113. A lot of thanks to Department of Irrigation and Drainage (DID) and Malaysian Meteorological Department (MMD) for the technical support and data provided.

\section{References}

1. T. Jiang, Y.D Chen, C. Xu, X. Chen, V.P. Sigh, Comparison of hydrological impacts of climate change simulated by six hydrological models in the Dongjiang Basin, South China, J Hydrol 336, 316333 (2007)

2. Intergovernmental Panel on Climate Change, Climate change 2007: synthesis report (2007)

3. Intergovernmental Panel on Climate Change, Climate change 2014: synthesis report (2014)

4. L. Zhang, Z.M. Ma, S.Z. Kang, Analysis of impacts of climate variability and human activity on stream flow for a river basin in arid region of northwest China, J. Hydrol 352(3-4), 239-249 (2008)

5. N. N. A. Tukimat, S. Harun, S.Shahid, Comparison of different methods in estimating potential evapotranspiration at Muda irrigation scheme of Malaysia, J. Agric. Rural Dev. Tropics and Subtropics 113(1), 77-85 (2012)

6. X.-J. Wang et al, Climate change and water resources management in Tuwei River basin of northwest China, Mitigation Adaptation Strategies Global Change 19(1), 107-120 (2014)
7. National Hydraulic Research Institute of Malaysia, Final Report: Study of the Impact of Climate Change on the Hydrologic Regime and Water Resources of peninsular Malaysia, Ministry of Natural Resources and Environment, Kuala Lumpur, Malaysia (2006)

8. K.V. Salzen, J.F. Scinocca, N.A. McFarlane, J. Li, J.N. Cole, D. Plummer, The Canadian fourth generation atmospheric global climate model (CanAM4) part I: representation of physical processes, Atmosphere-ocean (2013)

9. V.K. Arora, J.F. Scinocca, G.J. Boer, J.R. Christian, K.L. Denman, G.M. Flato, V.V. Kharin, W.G. Lee, W.J. Merryfield, Carbon emission limits required to satisfy future representative concentration pathways of greenhouse gases, Geophysical Research Letters 38(5), 3-8 (2011)

10. A. H. Nury, M. J. B. Alam, Performance Study of Global Circulation Model HADCM3 Using SDSM for Temperature and Rainfall in North-Eastern Bangladesh, J. Sci. Res. 6(1), 87-96 (2014)

11. Dibesh Khadka, Dinesh Pathak, Climate change projection for the marsyangdi river basin, Nepal using statistical downscaling of GCM and its implications in geodisasters, Geoenvironmental Disasters 3, 15 (2016)

12. Pedro Lopes, Assessment of statistical downscaling methods - application and comparison of two statistical methods to a single site in Lisbon, Earth and Environmental Science, 6 (2009)

13. N. N. A. Tukimat, S.Harun, S. Shahid, Modeling Irrigation Water Demand in a Tropical Paddy Cultivated Area in the Context of Climate Change, Journal of Water Resources Planning and Management 143(7), (2017)

14. Zulkarnain Hasan, Sobri Harun, Application of statictical downscaling model for long lead rainfall prediction in Kurau River Catchment of Malaysia, Malaysian Journal of Civil Engineering 24(1), 1-12 (2012)

15. Z. Hassan, S. Harun, S. Shamsudin, Application of SDSM and LARS-WG for simulating and downscaling of rainfall and temperature, Theoretical and Applied Climatology 116, 243-257 (2014)

16. J. Suhaila, S.M. Deni, W Zin, A.A. Jemain, Spatial patterns and trends of daily rainfall regime in Peninsular Malaysia during the southwest and northeast monsoons : $1975-2004$, Meteorology Atmospheric Physics 110, 1 - 18 (2010)

17. Malaysian Metrological Deparment (MMD), Malaysia Scientific report: Climate Change Scenarios for Malaysia 2001-2009, MetMalaysia Office Department, Malaysia (2009)

18. T.B. McKee, N.J. Doesken, J. Kleist, The Relationship of Drought Frequency and Duration to Time Scales, Conference on Applied Climatology 8th,179-184 (1993) 